\title{
Prediction of mango hopper, Idioscopus nitidulus (Walker) using hybrid modelling in Konkan region
}

\author{
A. Y. MUNJ ${ }^{* 1}$, V. N. JALGAONKAR ${ }^{1}$, B. R. SALVI ${ }^{1}$, A. L. NARANGALKAR ${ }^{1}$, J. S. CHOUDHARY ${ }^{2}$, \\ MADHUMITA KUMARI ${ }^{2}$, S.S. MALI ${ }^{2}$ and BIKASH DAS ${ }^{2}$ \\ ${ }^{*}, 1$ Dr. B.S. Konkan Krishi Vidyapeeth, Dapoli 415712, MS, ${ }^{2}$ ICAR Research Complex for Eastern Region, Research Centre, \\ Plandu, Ranchi-834010 (Jharkhand) India. \\ *Corresponding Author: Email: aymunj@rediffmail.com
}

\begin{abstract}
Mango hopper, Idioscopus nitidulus is the most destructive pest of mango in the India. Thus, aim of the study was to develop precise and easy early population prediction model of mango hopper for tropical mansoon climate conditions. Weekly occurrence data of mango hopper, I. nitidulus during five consecutive years (2014 to 2018) was used for developing hybrid of multiplicative seasonal autoregressive integrated moving average (SARIMA) and artificial neural network (ANN) model. The population of $I$. nitidulus increases in the month of January-February on flower panicles and October-November on new vegetative shoots in the region. The linearity in the time series data was best fitted with $\operatorname{SARIMA}(0,0,2)$ $\times(0,1,1)_{52}$ model as their correlation values are not outside the confidence intervals $(\mathrm{Cl})$ limits. Further ANN modeling was done for fitting the SARIMA residuals. The fitted values of model prediction and the actual values of year 2017-2018 flowering season (SMW36-52 of 2017 and SMW 1-13 of 2018) were used for testing of prediction efficiency. The performance of the two models in respect to model fitting and effectiveness of SARIMA and hybrid SARIMA-ANN model was compared by evaluating diagnostic statistics of MSE, RMSE, MAE and MAPE. The best fitted developed hybrid model in present study and the data predicted by model was matched with actual data of mango hopper incidence during the year 2017-18. Hybrid model developed in this study will help to predict hoppers population in advance, thus provide a direction for planning of timely prevention and development of effective management strategies which will help to minimize the use of hazardous pesticides.
\end{abstract}

Key words: Mango, hybrid modelling, population dynamics, time series forecasting

Importance of Mango (Mangifera indica L.) in India can be expressed by its allocation as the king of fruits. It is an economically important fruit crop and grown from tropical to warm subtropical region. In world mango production, India is at number one, and it contributes about $50 \%$ of the global supply with more than 18 million tonnes of mango production (NHB, 2016). Besides the world's largest producer, India suffers great losses of mango yield due to stresses exerted by many biotic and abiotic factors. Major constraints to the decreased mango production are increased incidence of insect pests and diseases in mango. Worldwide, about 492 species of insects have been reported on mango, out of which 188 insect pests are reported from India (Pena et al., 1998). Among the reported pests, very few are the major pests. Among the major insect pests, mango hoppers (Amritodus atkinsoni Leth, Idioscopus clypealis Leth and Idioscopus nitidulus Walk) are causing serious damage all over India (Rahman et al., 2007). Hoppers cause extensive damage to the mango, as it continues to damage in every stage of plant from development of new leaves, flowering till fruit setting. Hoppers lay eggs into the midrib of young leaves at the underside and on inflorescence and even in petioles. Both the adult and nymphs feed on vegetative flush by sucking the sap mostly from young leaves, tender shoots, inflorescence and also the rachis of young fruits. The affected florets turn brown and dry up resulting in non setting of fruits. Excessive feeding on rachis leads to the immature fruit drop. The hopper incidence is observed throughout the year but the high incidence is observed during the emergence of vegetative flush and flowering period. The excessive sap sucking by number of nymphs and adults may cause severe yield loss up to 100\% (Bana et al., 2018). They also cause damage to the plant by excreting large amount of "Honeydew"; on which black sooty mould (Capnodium mangiferae) develops giving blackish appearance to all infected plant parts (Munj, 2016). 
The population dynamics of insect pests are much dependent upon the prevailing environmental conditions such as temperature, relative humidity and precipitation (Moanaro and Choudhary, 2016). Besides the availability of new leaves and flowers, weather parameters also play an important role in the population build up of hoppers. Accurate prediction of hoppers would enable prevention of outbreaks. It is difficult to investigate all the factors responsible for hoppers occurrence however, it is well known fact that combining two different models can improve the prediction accuracy by increasing the chance of capturing different factors in the series (Zhang et al., 2013). Available information on factors affecting population buildup of hoppers in mango is meager and even if available, it is based on simple correlation and regression of weather and population dynamics of hopper. The present study was aimed to develop a hybrid prediction model using time series based seasonal autoregressive integrated moving average (SARIMA) and machine learning based techniques, artificial neural network (ANN) to predict occurrence of mango hopper based on long time series data of mango hopper incidence.

\section{MATERIALS AND METHODS}

\section{Experimental field and data observations}

The present study was carried out during five consecutive years (2014 to 2018) in the two fixed mango orchards of Alphanso variety at Regional Fruit Research Station (RFRS) Vengurla, Maharashtra, India (15 $512 \mathrm{~N}$ latitude, $73^{\circ} 392 \mathrm{E}$ longitude, elevation $11 \mathrm{~m} \mathrm{AMSL}$ ). The study location falls under typical tropical monsoon climate condition of Konkan region of Maharashtra. The area receives $3194.84 \mathrm{~mm}$ annual average rainfall with mean $23.7^{\circ} \mathrm{C}$ and $31.9^{\circ} \mathrm{C}$ minimum and maximum temperature, respectively (Anonymous, 2019). The monsoon in the study location onsets in the first week of June month. The selected orchards were kept free from application of any insecticide and fungicides during the study period. Five shoots/flower panicles were selected randomly from each of four quadrants and therefore a total of 20 shoots/ flower panicles were chosen from a tree. Total five trees were selected randomly from each orchard for recording observations. Thus, 100 shoots/ flower panicles were sampled per week from each orchard. Total number of hoppers (nymphs and adults) were counted and averaged in to hoppers per shoot/flower panicle for final analysis. The species of mango hopper was recorded and identified as Idioscopus nitidulus (Walker) (=Idioscopus niveosparsus (Lethierry)) (Hemiptera: Cicadellidae) infesting on young leaves and flower panicles in region. Daily data on weather variables including the mean, minimum and maximum temperature, the minimum and maximum humidity and the rainfall were recorded throughout the study period through meteorological observatory installed at research farm of RFRS, Vengurla.

\section{Model construction and integration}

The multiplicative seasonal autoregressive integrated moving average (SARIMA) model was developed from weekly time series data (2014-2018) of mango hopper incidence and weather data (Box et al., 2008). A seasonal ARIMA model is expressed as SARIMA (p, d, q) (P, D, Q)s, where $\mathrm{p}$ is order of autoregressive and $\mathrm{P}$ is the seasonal autoregressive parts; $d$ and $D$ are the order of integration and seasonal integration, respectively; $\mathrm{q}$ is the order of moving average and $\mathrm{Q}$ is seasonal moving average and finally s is the length of the seasonal period. Seasonal and non seasonal auto-regressive and moving-average terms for stationarity of time series was checked using autocorrelation function (ACF) and partial autocorrelation function (PACF) plots. The best model was identified by performing Akaike's information criterion (AIC) and the $p$ value $<0.05$ was used as a cut-off for statistical significance (Box et al., 1994). The SARIMA modeling was performed using the SPSS v. 21 (IBM, SPSS version, 21). Information generated from SARIMA was then used to compute the residual series as the target series of artificial neural networks (ANNs).

ANNs are computing system of flexible frameworks for modelling enormous non-linear interconnected structures which can be used for describing and forecasting of time series data (Cross et al., 1995). This model can perfectly fits in the definition of a good non-linear model (Gooijer and Kumar, 1992). In present study, we used Multilayer Perceptron Network toolbox of SPSS v. 21 (IBM, SPSS version, 21). Before modeling, we divided the target series into a training subset, and testing subset using the default random division function. The ratios for training, and testing were set to 0.70 , and 0.30 , respectively. Hybrid SARIMAANNs model was constructed based on methodology described by Zhang (2003). In SARIMA-ANN model, we combined the linear and nonlinear part of the model. In this two step methodology, SARIMA Model has been used to analyse the linear part of the actual data in the first step and then artificial neural networks model is used to model the residuals from SARIMA with nonlinearity. We selected the weekly estimated number of hoppers at time variable $t$ from SARIMA model. In the study, data series from flowering 
Table 1: Best fitted parameter estimates and their testing results of the SARIMA model

\begin{tabular}{llllll}
\hline Model parameters & & Coefficient & Standard error & $\mathrm{t}$ & $p$ value \\
\hline Non-seasonal legs $(0,0,2)$ & MA1 & 0.87 & 0.07 & -12.84 & 0.00 \\
& MA2 & 0.32 & 0.06 & -4.81 & 0.00 \\
Seasonal legs $(0,1,1)_{52}$ & Seasonal MA1 & 0.85 & 0.31 & 2.49 & 0.01 \\
\hline
\end{tabular}

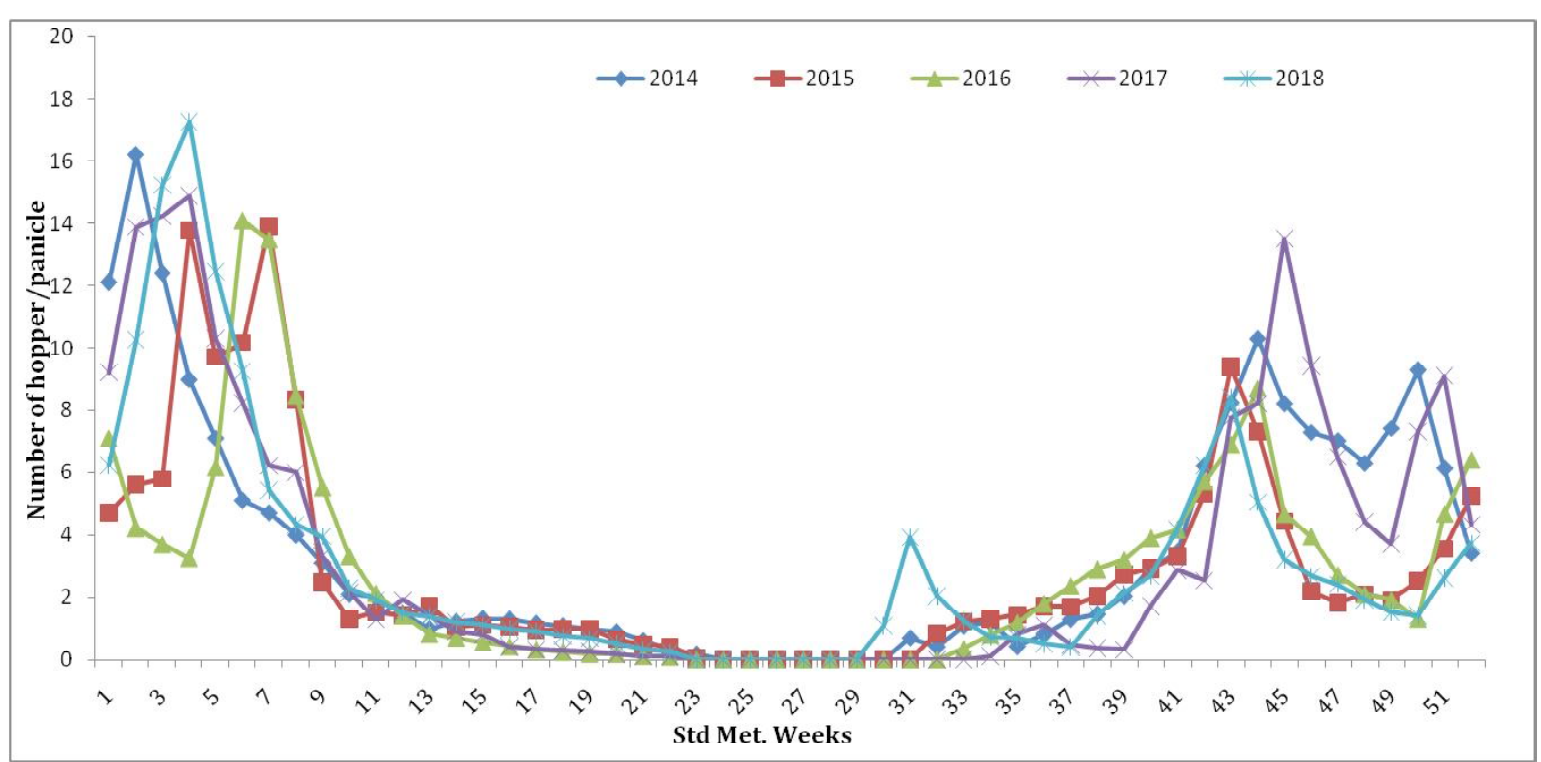

Fig. 1. Weekly observed number of mango hopper, I. nitidulus per shoot/flower panicle on mango during year 2014 to 2018 .

season of year 2017-18 were matched from models predicted population of mango hopper, I. nitidulus of same time.

Performance of the two models, SARIMA model and hybrid SARIMA-ANN model was compared in respect to model fitting and effectiveness. Different diagnostic statistics including coefficient of determination $\left(\mathrm{R}^{2}\right)$, mean square error (MSE), root mean square error (RMSE), mean absolute error (MAE), mean absolute percentage error (MAPE) were evaluated using the formulae described by Vennila et al. (2017).

\section{RESULTS AND DISCUSSION}

The data set of mango hopper incidence recorded at RFRS, Vengurla from January 2014 to December 2018 was used for model fitting (Fig. 1). The two peaks, one in the month of January-February and second in the month of October-November were observed in a year on the mango in the region. Very low population of mango hopper was observed during the months of March to September. This is due to available phonological stages of mango when new leaves and flowers were readily available (Bana et al., 2018). Weather parameters also play an important role for determining growth and distribution pattern of hoppers
(Debnath et al., 2013; Pushplatha et al., 2008). Minimum temperature, relative humidity, rainfall and wind velocity reported significant negative correlation with mango hoppers population dynamics (Bana et al., 2018; Zagade and Chaudhari, 2010). Significant negative correlation of mango hoppers with evening $\mathrm{RH}$ (' $r$ ' $=-0.66$ and -0.69 , $\mathrm{P}<.0 .01$ ) in Baneshan and Dashehari cultivars of mango, respectively reported by Kumari et al. (2008). Hopper population shoot-up with increase in maximum temperature and decreasing with increase relative humidity reported in agro-climatic conditions of Haridwar (Varshneya and Rana, 2008). The ACF and PACF plots of best identified SARIMA model are displayed in Fig. 2 which showing that correlations fell around zero and within their $95 \%$ confidence intervals after one order of differencing. Both plots of ACF and PACF suggest that stationarity in data series was achieved before searching best fitted SARIMA model.

The fitted parameters of seasonal ARIMA are shown in Table 1. The best fitted model was SARIMA $(0,0,2) \times(0$, $1,1)_{52}$ model for mango hopper population prediction in Konkan region. As their correlation values are not outside the confidence interval (CI) limits, the residual error is considered to be white noise indicating that this model is 
Table 2: Models performance results in the fitting and validation (2017-18) part of hopper population prediction.

\begin{tabular}{lllll}
\hline Prediction & \multicolumn{2}{c}{ Fitting error statistics } & \multicolumn{2}{c}{ Validation error statistics } \\
Statistical error & SARIMA & SARIMA-ANN & SARIMA & SARIMA-ANN \\
\hline $\mathrm{R}^{2}$ & 0.90 & 0.91 & 0.92 & 0.94 \\
MSE & 1.33 & 1.23 & 1.74 & 1.30 \\
RMSE & 1.15 & 1.11 & 1.31 & 1.14 \\
MAE & 0.93 & 0.90 & 0.96 & 0.73 \\
MAPE & 0.53 & 0.51 & 0.33 & 0.28 \\
\hline
\end{tabular}
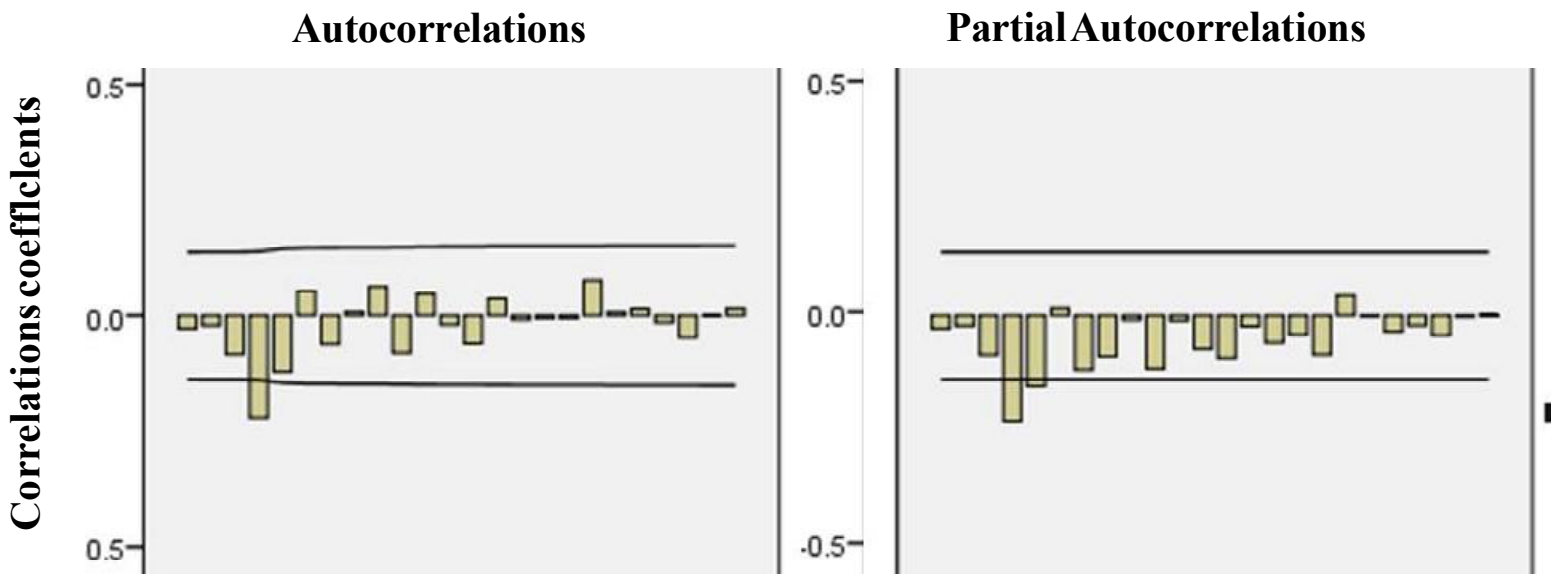

Fig.2: Graphs of residuals of Autocorrelations Function (ACF) and Partial Autocorrelations Function(PACF).

appropriate for hopper population prediction.

The parameters of optimum ANN model of SARIMA residuals were fitted with 4 hidden units of hyperbolic tangent activation function. The $\mathrm{R}$ values were found significant with value of 0.65 . All MSE values of the training, and testing subsets were found to be relatively small.

In construction of Hybrid SARIMA-ANN model, the prediction accuracy of the ANN model depends on the smoothing factor which can be assess by dividing each data set into two sample of training and testing. The training data set is used exclusively for model development and then the test sample is used to evaluate the established model.

The fitted values of model prediction and the actual values of year 2017-2018 flowering season (SMW36-52 of 2017 and SMW 1-13 of 2018) were used for testing of prediction efficiency. The prediction error of the hybrid model in fitting part and validation part was lower than the SARIMA model, as MSE, RMSE, MAE and MAPE showed (Table 2). Comparison curves of SARIMA, hybrid SARIMAANN and actual mango hopper incidence is displayed in Fig. 3.

The model curve displays the point to point comparison of actual hopper population and predicted population in SARIMA model and hybrid SARIMA-ANN model. The actual hopper population and both the model prediction not showed any particular pattern of occurrence throughout the year. Hopper population starts increasing from $40^{\text {th }} \mathrm{SMW}$ and slight lower population predicted through hybrid model in SMW 43 than the real incidence. Sudden increase in the population in $44^{\text {th }}$ week was displayed by both the models and rapid population decrease occurs in $45^{\text {th }}$ week. Same pattern of increase and decrease in population shown in SMW 49 and 50 of the year 2017. In the year 2018, maximum hopper population predicted in SMW 4 by both SARIMA and hybrid models which match with the actual data. Thus, from the above curve we can conclude that fluctuation in hopper population occurs weeklybut not any particular seasonal pattern was observed for increasing or decreasing population. Thus, hybrid SARIMA-ANN model performs better than SARIMA model for this time horizon. Time series data analysis for forecasting is an important area for prediction and forecasting from past observations (Boopathi et al., 2015). Hybrid modelling can be used for forecasting and prediction of the incidence of different insects (Boopathi et al. 2015).

It could not be possible to compare current findings 


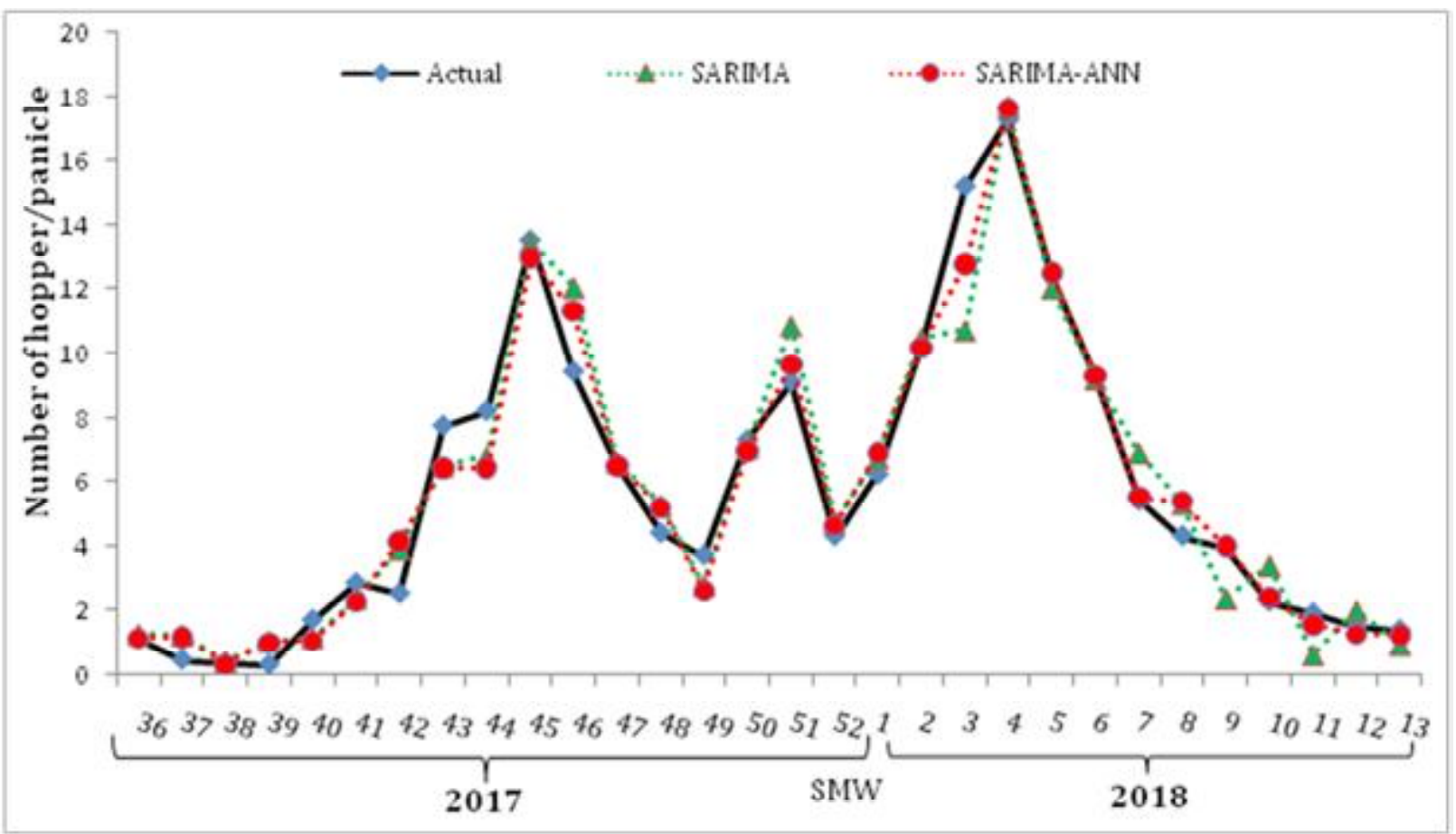

Fig. 3: Model fitting and prediction values with actual hopper population on mango during the year 2017-2018.

of the study with published literature due to absence of time series based analysis in India on mango hoppers however, the time series based analysis extensively applied on data series of litchi stink bugs, greenhouse whitefly, Trialeurodes vaporariorum, leopard moth, Zeuzera pyrina etc. (Boopathi et al. 2015; Chiu et al., 2019; Hegazi et al., 2014) The proposed hybrid model is easier to use than the other models found in the literature for mango hopper prediction in other ecologies (Debnath et al., 2013; Pushplatha et al., 2008) and can improve the applicability to the end users for management of mango hoppers.

\section{CONCLUSION}

The objective of present study was to develop a reliable and accurate combined hybrid seasonal ARIMAANN model to predict the incidence of mango hopper, $I$. nitidulus under tropical monsoon climate conditions of Konkan region. Using hybrid model developed in present study, it may be possible to predict the incidence of mango hoppers well in advance for effective planning and development of management strategies against hopper incidence on mango. Importantly, this model could also be serving as a template for prediction of other pests of mango crop.

\section{ACKNOWLEDGEMENT}

The authors are thankful to Indian Council of Agricultural Research(ICAR), New Delhi for funding through National Innovations on Climate Resilient Agriculture
(NICRA) project for conducting the present study. Also, the authors are thankful to the Director of Research, Dr. Balasaheb Sawant Konkan Krishi Vidyapeeth, Dapoli, Maharashtra for providing the facilities for conducting the study.

\section{REFERENCES}

Anonymous. (2019). Report of Research Review Committee of Department of Plant Physiology, Dr. B.S.K.K.V., Dapoli.

Bana, J.K., Kumar, S. and Sharma, H. (2018). Diversity and nature of damage of mango insect-pests in south Gujarat ecosystem. J. Ent. Zool. Studies, 6(2): 274-278.

Boopathi, T., Singh, S.B., Manju, T., Ramakrishna, Y., Akoijam, R.S., Chowdhury, S., Singh, N.H. and Ngachan, S.V. (2015). Development of temporal modeling for forecasting and prediction of the incidence of Lychee, Tessaratoma papillosa (Hemiptera: Tessaratomidae), using time-series (ARIMA) analysis. J. Insect Sci., 15(1): 55-59.

Box, G.E.P., Jenkins, G.W and Reinsel, G.C. (1994). Time series analysis, 3rd ed. South Windor, New SouthWales, Australia.

Box, G.E.P., Jenkins, G.W., and Reinsel, G.C. (2008). Time series analysis, $4^{\text {th }}$ ed. John Wiley \& Sons, Inc., Hoboken, New Jersey, Canada.

Chiu, L. Y., Rustia, D. J. A., Chen, Y. L. and Lin, T.T. (2019). Modelling and Forecasting of Greenhouse Whitefly 
Incidence Using Time-Series and ARIMAX Analysis. IFAC-PapersOnLine, 52 (30); 196-201.

Cross, S.S., Harrison, R.F. and Kennedy, R.L. (1995). Introduction to neural networks. Lancet, 346: 1075-79.

Debnath, M.K., Seni, A. and Sharma, H.L. (2013). Population dynamics of mango hopper, Amritodus atkinsoni on mango plant, Mangifera indica. Indian J. Plant Prot., 41: 308-313.

Gooijer,J.G.D. and Kumar, K.(1992). Somerecent developments in non-linear time series modeling, testing, and forecasting. Int. J. Forecast., 8: 135-156.

Hegazi, E., Khafagi, W. E., Konstantopoulou, M., Raptopoulos, D., Tawfik, H.,AbdEl-Aziz, G. M., AbdEl-Rahman, M., Atwa, A., Aggamy, E., and Showeil, S. (2009). Efficient mass-trapping method as an alternative tactic for suppressing populations of leopard moth (Lepidoptera: Cossidae). Ann. Entomol. Soc. Am., 102, 809-818.

Kumari, A., Lakshmi, D., Reddy, B.K.M.S. andReddy, L.M. (2009). Influence of abiotic factors on the incidence of hopper and chemical control strategies in mango. Karnataka J. Agric.Sci., 22: 601-602.

Moanaro, L. and Choudhary, J. S. (2016). Influence of weather parameters on population dynamics of thrips and mites on summer season cowpea in Eastern Plateau and Hill region of India. J. Agrometeorol., 18 (2): 296-299.

Munj, A.Y. (2016). Population dynamics and management of mango hopper Idioscopus niveosparsus Leth under Konkan region of Maharashtra. (Doctoral Thesis, MPUAT, Udaipur, Rajasthan).

National Horticulture Board. (2016). Horticultural statistics at a glance 2016. http://nhb.gov.in/statistics/Publication/ Horticultural\% 20Statistics\% 20at\% 20a\% 20Glance\% 202016_468\%20page.pdf.

Pena, J.E., Mohyuddin, A.I. and Wysoki, M.(1998). A review of the pest management situation in mango agroecosystem. Phytoparasitica, 26(2): 129-148.

Pushpalatha, S., Kathirvelu, C. and Nachiappan, R.M. (2008), Correlation of seasonal incidence of mango hopper, Amritodes atkinsoni and weather parameters on certain varieties of mango. Ind. J. Trop. Biodiv., 15: 81-83.

Rahman, S., Azizur and Shrivastava, K. (2007). Mango hoppers: Bioecology and management- A Review. Agric. Rev., 28(1): 49-55.Varshneya, A. and Rana, K.S. (2008). Effect of some abiotic factors on population buildup of Idioscopus clypealis (Lethierry) in western Uttar Pradesh. J. Environ. Bio., 29: 811-812.

Vennila, S., Singh, G., Jha, G.K., Rao, M.S., Panwar, H. and Hegde, M. (2017). Artificial neural network techniques for predicting severity of Spodoptera litura (Fabricius) on groundnut. J. Environ. Bio., 38(3):449-456.

Zagade, M.V. and Chaudhari, J.N. (2010). Impact of meteorological parameters on population dynamics of mango hopper in high rainfall zone of Konkan region. J. Agrometeorol., 12(1):111-113.

Zhang, G., Huang, S., Duan, Q., Shu, W. and Hou, Y. (2013). Application of a Hybrid Model for Predicting the Incidence of Tuberculosis in Hubei, China. PLoSONE, 8(11): e80969.

Zhang, G.P. (2003). Time series forecasting using a hybrid ARIMA and neural network model. Neurocomputing, 50: $159-175$. 